\title{
UNIDIRECTIONAL COUPLED FINITE ELEMENT SIMULATION OF THERMOELASTIC TCP-DISPLACEMENT THROUGH MILLING PROCESS CAUSED HEAT LOAD
}

\author{
S. Brier ${ }^{1,2 *}$, J. Regel ${ }^{1}$, M. Putz ${ }^{1,2}$, M. Dix ${ }^{1,2}$ \\ ${ }^{1}$ Chemnitz University of Technology, Institute for Machine Tools and Production Processes, Chemnitz, Germany \\ ${ }^{2}$ Fraunhofer Institute for Machine Tools and Forming Technology IWU, Chemnitz, Germany \\ ${ }^{\star}$ Corresponding author; e-mail: steffen.brier@iwu.fraunhofer.de
}

\begin{abstract}
The paper presents a numerical simulation of thermal induced tool displacement during milling operation. An unidirectional finite element model is developed which consists of two sections. A CFX model and a thermal transient model. With the aid of CFX module, the conjugated heat transfer between milling tool and coolant fluid is described. The result of these efforts is the body temperature field of the end mill cutter due to thermal load, which is the thermal fingerprint of the cutting process. Subsequently the calculated body temperature field is linked with a transient-structural module to calculate the resulting thermal elastic displacement of the milling cutter. The thermo-elastic displacement of the tool is determined by examining a pilot node at the tip of the end mill, whose displacement is calculated in relation to the global coordinate system of the model.
\end{abstract}

\section{Keywords:}

CFD; FEM; Tool Center Point; FEA; TCP-displacement; Heat source; Thermal displacement; Machine Tools; Milling; Design of experiments; DOE;

\section{INTRODUCTION}

In the process of machining, a significant amount of heat is introduced into the cutting tool and its clamping system. It is approximately $10 \%$ of the total energy [Pabst 2008]. The structure in concern reacts with a thermally induced deformation, which significantly reduces the machining accuracy. This deformation is expressed in an axial and radial displacement of the tool centre point (TCP).

The models developed so far focused on the approximation of the behaviour of the individual components of milling machine tool during machining. Putz et al. investigated the effect of the coolant lubricant charge on the thermal state, in which the influence of different cooling strategies on the temperature fields in the tool and machine was investigated. In these studies, the focus was placed on the thermal behaviour of the individual components in the working area of the milling machine and thus no statement was made about the TCP displacement [Putz 2019].

Sauerzapf et. al [Sauerzapf 2020] described a macroscopic machine model and the displacement of the TCP due to heat input. The work shows the simulation of the thermal behaviour of machine tools and online correction of the TCP-displacement. Though, the work excluded the tool and holder structure in the simulation.

Klocke et. al included the chip formation process as well as the coolant jet influence in the focus of their research in the field of fluid-structure interaction (FSI). The major aim was to prevent the difficulties regarding remeshing, which is necessary to simulate material partition. A Finite Element
(FE) model with coupled Euler-Lagrangian approach was introduced, which enables the coupling of chip formation simulation and fluid simulation [Klocke 2017].

In recent years, the modelling of drilling operations attracted attention. The work of Oezkaya [Oezkaya 2019] developed a novel approach to link structural and fluid mechanical simulation with each other to establish a valid model for prediction of temperature distribution in the drill. This work offers a very specific way to investigate the fluid supply for deep hole drilling process.

Semmler et. al [Semmler 2014] investigated the thermal deformation of cutting tools. They showed that heat flows from thermal energy produced during machining process cause significant thermo-elastic displacements of the TCP. The approach considered cutting under dry conditions without the use of coolant fluid to reduce the maximum amount of tool temperature.

A mathematically determinable axial and radial displacement of the TCP is necessary for a reliable and safe compliance with the manufacturing tolerances and a later compensation by means of a machine tool control. A unidirectional FSI model has been developed for the use of cooling lubricant in the form of a full-jet cooling system. It combines a two-phase turbulence model of a rotating cutting tool under full-jet cooling [Topinka 2020] with the structural-mechanical simulation. The result of these efforts is a simulation of the TCP displacement depending on the processinduced machining heat, cutting tool speed of rotation and the applied cooling lubricant volume flow. Main purpose of 
the research efforts is the acquisition of characteristic diagrams with the aid of FSI model. The FEM part is described in this paper. In the process, displacement data of the FEM model is the foundation for further processing to calculate a quasi-static thermal state of TCP displacement and derivation of characteristic diagrams. These diagrams should be finally implemented in the machine control system to establish an online compensation of TCP displacement during milling process. Other cooling methods beside full-jet cooling, like Minimum Quantity Lubrication (MQL) should also be modelled via FSI approach to allow the characteristic diagram construction for this method as well. Therefore, the development of FSI model plays a significant role in additional research activities.

\section{COUPLED FSI FEM SIMULATION APPROACH}

The full jet cooling of a rotating end mill is a very complex problem, which cannot be modelled without simplifications. The task requires the appropriate simplification of the geometry, the choice of suitable boundary conditions and models to describe the dual-phase fluid flow accurately. A significant model simplification regarding geometry is not possible in the case of this transient cooling simulation. It is mandatory to prevent the cutter surface, because a significant change of the geometry would lead to unrealistic flow field around the cutter. Only details are simplified, which are not important for the flow formation like screws and threads or small surface details.

For modelling the multiphase approach the volume of fluid (VOF) method is applied in ANSYS CFX ${ }^{\circledR}$. The VOF method is part of the Euler-Euler modelling framework. In the framework, all encountered phases are treated as continuous and immiscible fluids. A requirement for the application and validity of the model is that the fluids are not allowed to interpenetrate each other. This is a valid assumption in case of coolant simulation, hence the tool surrounding air and the coolant fluid are modelled as continuous phase. To deal with the turbulence is significant for heat transfer between solid and fluid. Therefore, Menter's Shear Stress Transport turbulence model (SST) is used [Menter 94]. It combines the $k-\omega$ model (good near walls, weak at freestreams) and the $k-\varepsilon$ model (good for freestream, weak near walls) with each other to avoid the disadvantages of each model. To track the reality in a properly manner, the fluid flow is considered to show buoyancy effects as well as buoyancy turbulence.

The cutting process simplification used in this model is related to heat load application. Due to the lack of simulating the chip formation under jet cooling, the heat load was applied as constant heat flow via small facets on the rake fake of the cutter. These areas are engaged during the real cutting process, to imitate the heat flux induced by the chip formation. Heat transfer is calculated with the aid of total energy model, which includes high-speed energy effects.

Ambient and fluid temperature were considered to be $22^{\circ} \mathrm{C}$ as initial value. All relevant thermal and flow related material parameters as specific heat capacity or thermal conductivity are set for each individual material of all parts of the model. The CFX model consist of several different domains and is realized with transient rotor stator approach. The Fig. 1 shows the different Computational Fluid Dynamics (CFD) domains of the CFX model. A calculation of the thermally induced linear expansion of a solid flowed around by fluid flow is not possible in the CFX module of ANSYS. Only the solid-state temperatures due to the conjugate heat transfer can be computed in CFX and the calculation of the resulting
TCP displacement has to be done afterwards in ANSYS Workbench transient structural module.

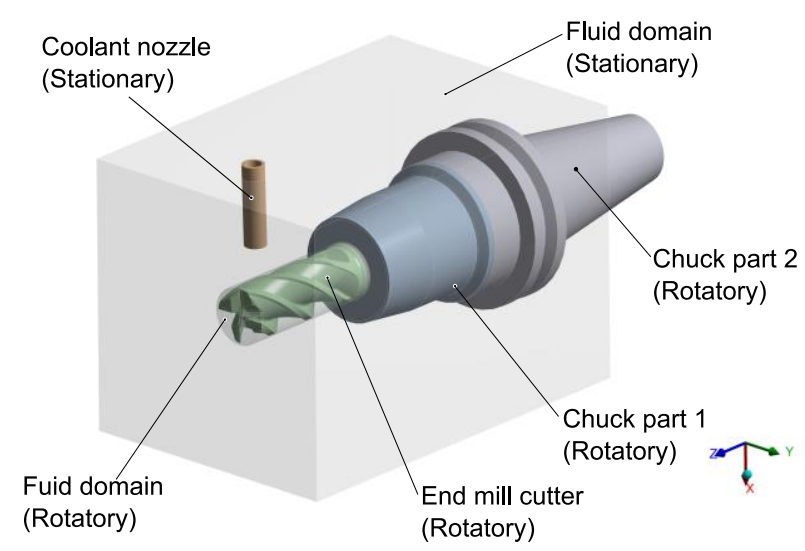

Fig. 1: CFD domains of FSI simulation

The path taken via the conjugated heat transfer is inevitable. Due to the thermal boundary conditions at the interface between the tool and the coolant flow, which are unknown a priori. The solution of the issue is the implementation of a one-way coupled FSI (Fig. 2) [Perng 2011]. In order to determine the displacement of the TCP it is firstly necessary to calculate the temperature field of the tool and afterwards transfer the calculated body temperatures to the mechanical module according to their coordinates. The CFX module determines the body temperature values and maps them to the mechanical mesh. It provides the body temperature for each node of the tool model at each time step. Subsequently the displacement of the TCP is calculated with the aid of these thermal boundary conditions. Previous tests provide a starting point for indicating the heat applied to the chip in contact with the chip [Putz 2019].

\section{BOUNDARY CONDITION}

The selection of the appropriate boundary conditions is the foundation for modelling with FEM methods. In the following, the applied boundary conditions are explained in detail to describe the used model in an extensive way. The CFD simulation is designed as transient and represents a time interval of 10 seconds. Time step size is 0.05 seconds. Main reason for restricting simulation time span upon $10 \mathrm{~s}$ is the time consuming character of the CFX calculation. It takes about 13 hours to solve only $10 \mathrm{~s}$ of tool cooling, a powerful desktop PC assumed.

The turbulence model used is the SST model of Menter, which can adequately represent turbulent flows in the boundary and free flow area [Menter 94]. Both fluids, the coolant and the surrounding air phase, are modelled as homogeneous continuous phases. The coolant is considered as a homogeneous liquid, to keep the level of detail within an acceptable range. In the multiphase model applied, the coolant is the primary phase. The density of the coolant is assumed to be $940 \mathrm{~kg} / \mathrm{m}^{3}$. The isotropic thermal conductivity is given as $0.16 \mathrm{~W} / \mathrm{mK}$ and the specific heat capacity is $1465 \mathrm{~J} / \mathrm{kgK}$. Second fluid phase air has a density of 1,185 $\mathrm{kg} / \mathrm{m}^{3}$ and an isotropic thermal conductivity of $2,6^{\star} 10^{-2}$ $\mathrm{W} / \mathrm{mK}$. The specific heat capacity is assumed to be $1,0044^{*} 10^{+3} \mathrm{~J} / \mathrm{kgK}$. The tool is made of tungsten carbide with a density of $14500 \mathrm{~kg} / \mathrm{m}^{3}$ and a Young-modulus of 650 $\mathrm{GPa}$. The isotropic thermal conductivity is $80 \mathrm{~W} / \mathrm{mK}$ and the specific heat capacity is $213,5 \mathrm{~J} / \mathrm{kgK}$. The coefficient of thermal expansion is defined as $5^{\star} 10-6 \mathrm{~K}^{-1}$. The chuck was modelled using hot work tool steel with an $\mathrm{E}$-modulus of 215 $\mathrm{GPa}$ and a density of $7850 \mathrm{~kg} / \mathrm{m}^{3}$. 


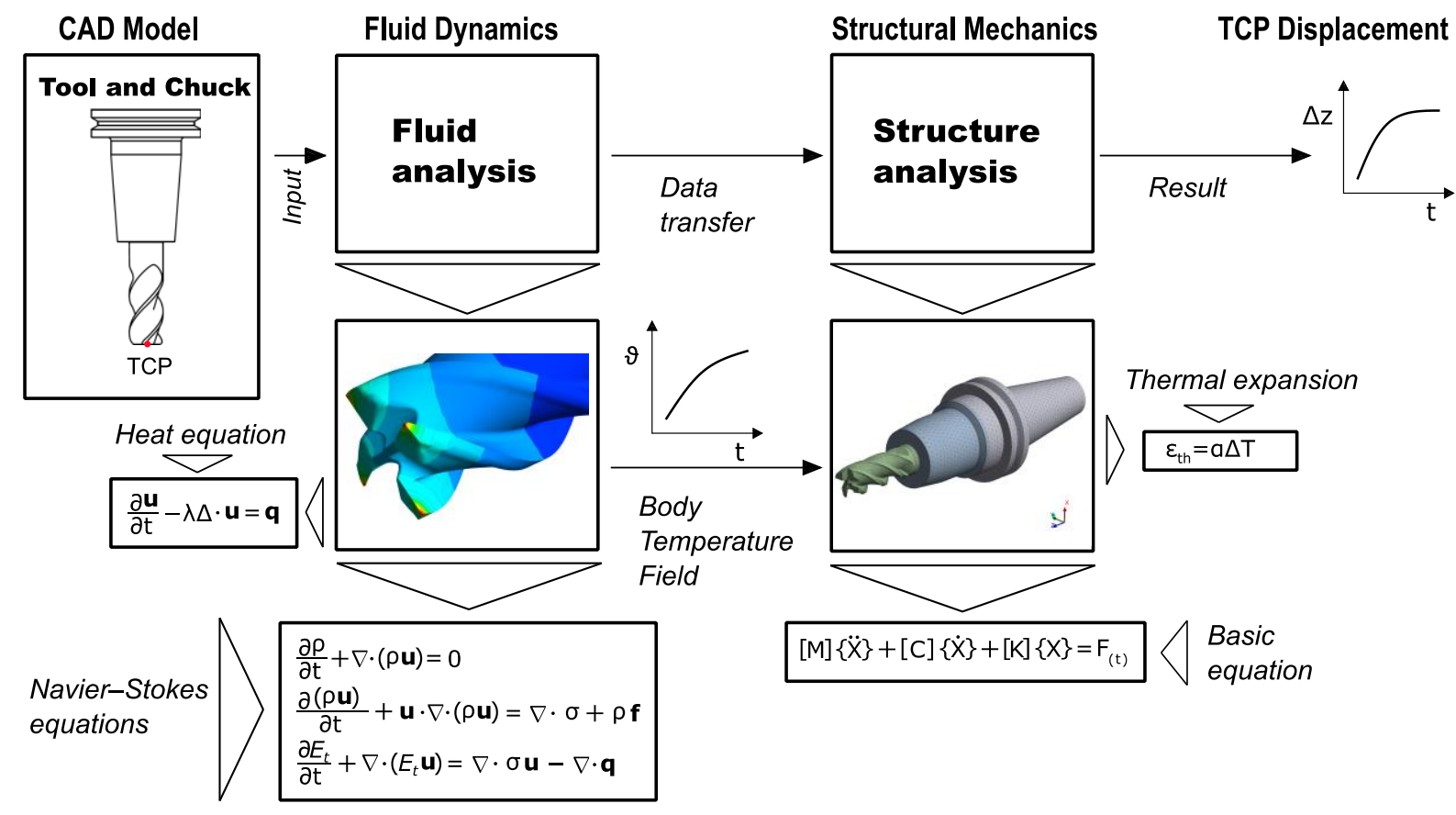

Fig. 2: FSI simulation scheme for TCP displacement calculation

The isotropic thermal conductivity and specific heat capacity are elementary for the calculation of heat conduction in solids. Used values are $26 \mathrm{~W} / \mathrm{mK}$ and respectively 460 $\mathrm{J} / \mathrm{kgK}$. About $11,7^{*} 10^{-6} \mathrm{~K}^{-1}$ is the coefficient of thermal expansion.

Two models, the thermal energy model and the total energy model can consider the heat transfer. In the present model, the total energy formulation was implemented. The approach of total energy equation considers the conservation of energy, which is a combination of internal, kinetic and potential energy (only for liquids).

The multi-domain CFD model consists of 253281 nodes and 1267372 elements. At time $t=0 \mathrm{~s}$, the temperature is defined as $22{ }^{\circ} \mathrm{C}$ for the end mill and chuck as initial condition. A heat transfer coefficient of $35253 \mathrm{~W} / \mathrm{m}^{2} \mathrm{~K}$ and a constant spindle temperature of $32^{\circ} \mathrm{C}$ are applied to represent the heat transfer from the spindle to the taper shank. A spindle temperature above the ambient is mandatory to establish a heat flow through the taper shank into the chuck and tool. The shrink fit connection is configured with a heat transfer coefficient of $2200 \mathrm{~W} / \mathrm{m}^{2} \mathrm{~K}$.

To represent machining process $6 \mathrm{~W} / \mathrm{mm}^{2}$ is applied as thermal load to the cutting edges area of the end mill cutter. They are defined as four single faces with an area of $0,55683 \mathrm{~mm}^{2}$ (corresponds to $2,2345 \mathrm{~mm}^{2}$ summed up). The coolant volume flow is defined with $3 \mathrm{l} / \mathrm{min}$ and is thereby in the range of full jet cooling.

The calculation of the thermally induced displacement takes place in the transient structural module. Due to the former mentioned fact that CFX cannot calculate any structural mechanical displacement. For the realization of the structural-mechanical simulation, the model had to be significantly simplified with respect to the number of elements. The reduced mesh consists of 197642 nodes and 133584 elements. The reason for this is the transfer of the transient body temperature field from the conjugate heat transfer of the CFD simulation. It provides a massive memory requirement, even with a reduced number of elements. Total simulation time corresponds to the CFD simulation and is equally 10 seconds, whereby the step size is specified as $0,25 \mathrm{~s}$. All solids are subject to the linear elastic material model (Hook's law). Applied boundary conditions in the structural module are the imported body temperature field from CFX and a remote displacement as a fixture in space. The remote displacement with a value of 0 in every axial and rotational direction allows a temperature degree of freedom and thermal displacement compared to the fixed support. It is extremely important because there is a heat flux from the taper shank towards the tool tip and a fixture of the taper shank with the common fixed support would stop the heat flux and would therefore falsify the resulting thermal induced displacement. The issue was circumvented with the aid of the remote displacement. As former mentioned allows a fixture without disturbing the thermal degrees of freedom and thermal caused displacements.

To determine the results of the displacement components single nodes located in close proximity to the TCP and other positions were selected using the extended component selection. This nodes allows the evaluation of the axial and radial displacement components and thus the representation of the displacement of the TCP and defined position of the cutter and chuck. All relevant model conditions and material properties of the materials used are shown in detail in Fig. 3.

\section{RESULTS}

The results of the CFD simulation of the coolant flow indicate a highly turbulent flow around the observed end mill. This can be clearly illustrated by showing the streamlines. They represent curves in the velocity field of a flow, whose tangent direction corresponds to the directions of the velocity vectors of the velocity field of the flow. They run tangential to the velocity field at every point. At an early point in time $(t=0.05 \mathrm{~s})$ the coolant does not surround the end mill which is being cooled. However, a quasi-stationary state has been reached after 5 seconds and the streamlines do not change significantly compared to the flow state at the end of the simulation after 10 seconds (Fig. 4). 
Air Material Properties:

\section{Density $\rho=1,185 \mathrm{~kg} / \mathrm{m}^{3}$}

Isotropic Thermal Conducivity $\lambda=2,6^{*} 10^{-2} \mathrm{~W} / \mathrm{mK}$ Specific Heat Capacity $c_{p}=1,0044^{*} 10^{+3} \mathrm{~J} / \mathrm{kgK}$

Coefficient of Thermal Expansion $\alpha_{\mathrm{th}}=0,003356 \mathrm{~K}^{-1}$ Dynamic Viskosity $\eta=1,831 * 10^{-5} \mathrm{~kg} / \mathrm{ms}$

\section{Coolant Material Properties:}

Density $\rho=940 \mathrm{~kg} / \mathrm{m}^{3}$

Isotropic Thermal Conducivity $\lambda=0,16 \mathrm{~W} / \mathrm{mK}$

Specific Heat Capacity $c_{p}=1465 \mathrm{~J} / \mathrm{kgK}$

Coefficient of Thermal Expansion $\alpha_{\mathrm{th}}=0,0007 \mathrm{~K}^{-1}$

Dynamic Viskosity $\eta=0,094 \mathrm{~kg} / \mathrm{ms}$

.

CFD Simulation Setup:

Analysis Type: Transient

Total Time: $\mathrm{T}=10 \mathrm{~s}$

Time Step Size: $\Delta t=0,05 \mathrm{~s}$

Turbulence Model: SST k- $\omega$

Multiphase Model: Homogenous with two Fluids

Heat Transfer Model: Total Energy

Nodes: 253281

Elements: 1267372

Boundary Conditions: Initial Conditions

$q_{c}=6 \mathrm{~W} / \mathrm{mm}^{2}$

aspindle $=35253 \mathrm{~W} / \mathrm{m}^{2} \mathrm{~K}$

ソ Spindle $=32^{\circ} \mathrm{C}$

a Tool-Chuck $=2200 \mathrm{~W} / \mathrm{m}^{2} \mathrm{~K}$

$\dot{\mathrm{V}}_{\text {coolant }}=3 \mathrm{l} / \mathrm{min}$

$\mathrm{n}=15001 / \mathrm{min}$

$\vartheta_{\text {coolant }}=22^{\circ} \mathrm{C}$

$A_{C}=4 \times 0,55683 \mathrm{~mm}^{2}$

$=2,2345 \mathrm{~mm}^{2}$

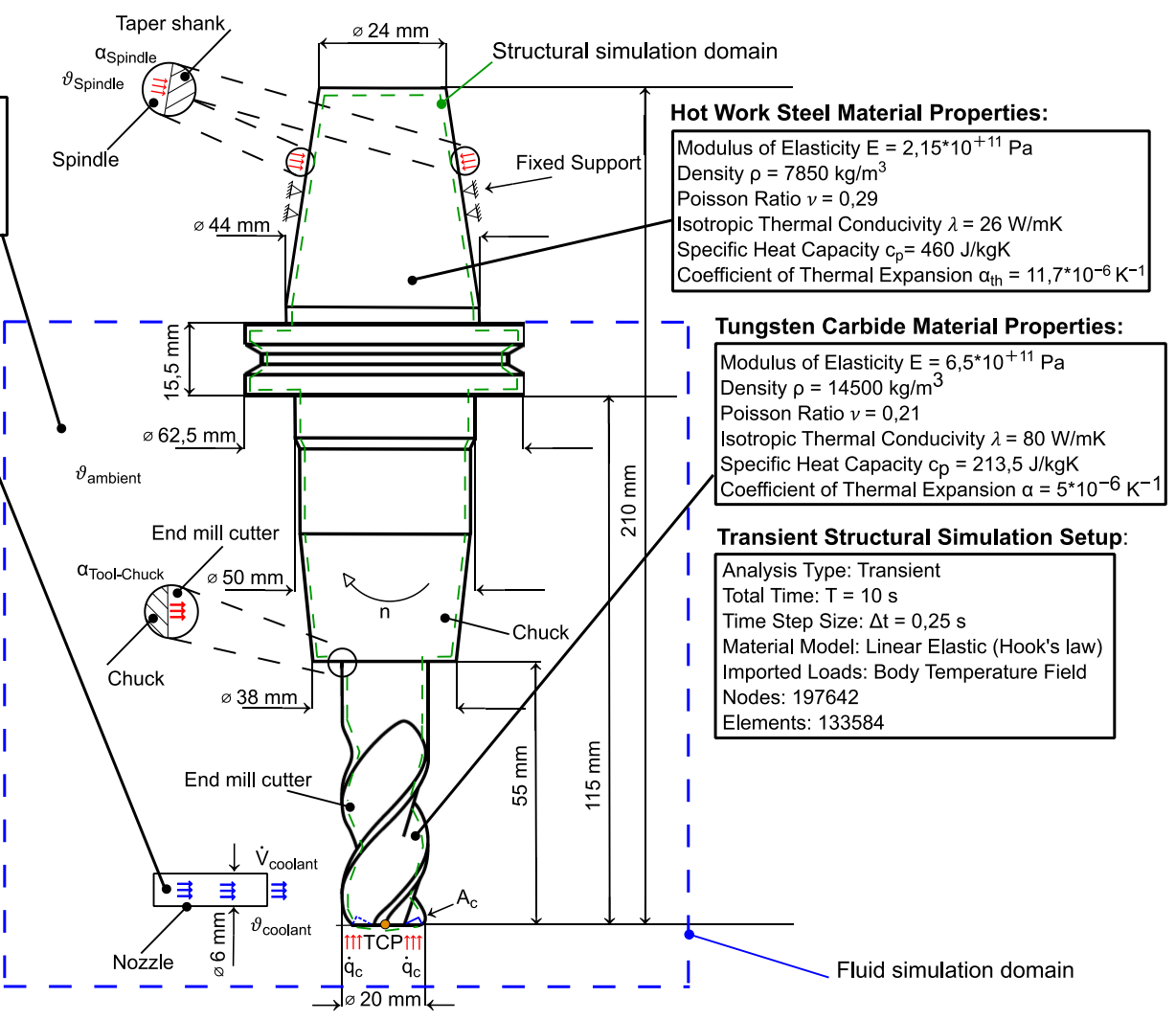

Fig. 3: Boundary and initial conditions of the FSI model
Despite coolant flowing around the whole surface of the milling cutter the temperature plot of the tool tip clearly shows the heat conduction of the solid body. The temperature continues to rise as time passes. The tool cutting edges heat up more and more caused by the thermal load respectively the process heat flow. It is supposed to represent the heat input from the machining process, and reach about $100{ }^{\circ} \mathrm{C}$ after 10 seconds simulation time. It can be assumed that the temperature will continue to rise, since a thermal equilibrium has not yet been reached at this point.

The wall heat flow is very small at the beginning of the simulation. The flow through the end mill cutter surface increases significantly as the simulation progresses and changes only slightly after 5 seconds compared to the wall heat flow at the end of the simulation. This effect is because of the time the flows needs to envelop the whole end mill cutter and establish a quasi-stationary state. The extremely unsteady state at the beginning of the cooling is reflecting in the wall heat flux. Wall heat flux is increasing, because the coolant needs time to moisten the cutter surface and absorb the heat.

The wall heat transport coefficient (HTC) is spatially very divergent at the beginning of the simulation. After a few seconds of simulation time, a nearly steady state is reached and a significant change of the value is no longer detectable after 5 seconds of coolant fluid flow. Then the surface of the tool is uniformly wetted and shows a more regular HTC at the tool surface.

Although the material model used for modelling the tool and the clamping device follows the ideal linear elastic Hook's model, the course of the axial displacement over time is non-linear. The heat flow is taken into account, which is transferred to the coolant and thus removes a part of the process heat (from the machining process) off the tool.
Therefore, the calculated axial TCP displacement shows a nonlinear behaviour over time and increases diminishingly with increasing simulation time. After 10 seconds simulation interval the axial displacement of the TCP reached a maximum value of $4,36 \mu \mathrm{m}$. Beside the calculated axial displacement, the plot (Fig. 5) illustrates the radial displacement as well. The calculated radial displacement in the region of tool tip is reaching $2,37 \mu \mathrm{m}$. In the area of the interface of tool holder shank the displacement is about $0,7 \mu \mathrm{m}$ after $10 \mathrm{~s}$. If the type of time dependant development is investigated, the behaviour shows a linear characteristic. This is due to the absence of coolant and the constant assumed heat load of the machine tool spindle. A closer look at the results of the radial displacement reveals an extremely flat trend within the calculated time span. The radial displacement in the middle of the cutter shows only a small value. Because of the slow thermal conductance, which is not able to increase the temperature in that tool region within such a short period of $10 \mathrm{~s}$. Testing simulations above $60 \mathrm{~s}$ duration show a similar behaviour like the tool tip, although on a significant lower level.

To gather a generalised testimony, it is scheduled to simulate the TCP displacement by means of a full factorial experimental design. Subsequent the TCP time dependent behaviour will be extrapolated until a steady state is reached. Steady state values are the basis for the application of response surface method. At the end, an arithmetic expression will be defined to cover a wide span of the varied parameter. With the aid of these characteristics a generalised statement regarding TCP displacement is possible. The characteristics show influence of the heat load due to cutting, the tool rotation and coolant flow volume on the TCP displacement. 


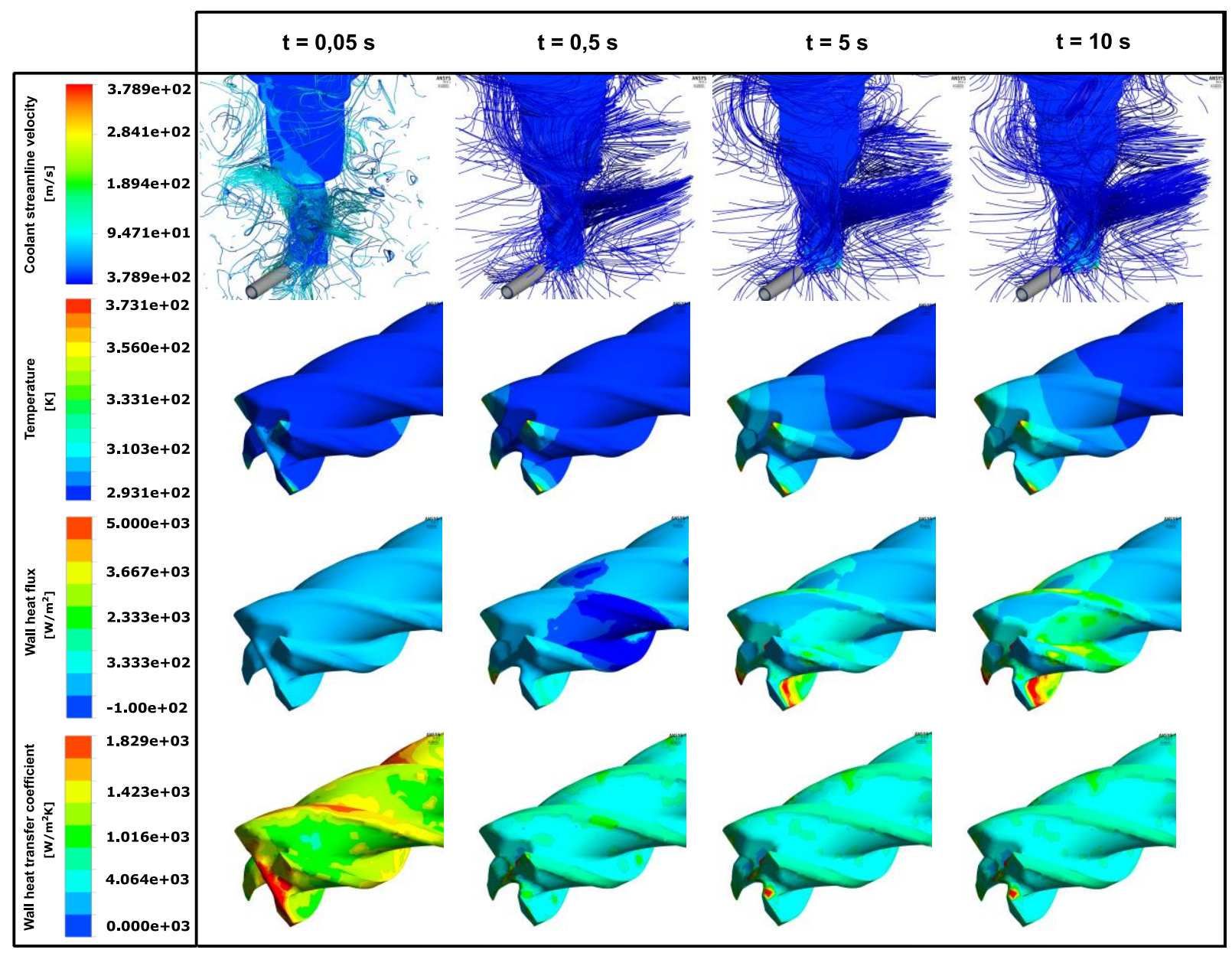

Fig. 4 : Results of the CFD Simulation of jet cooling of an end mill cutter

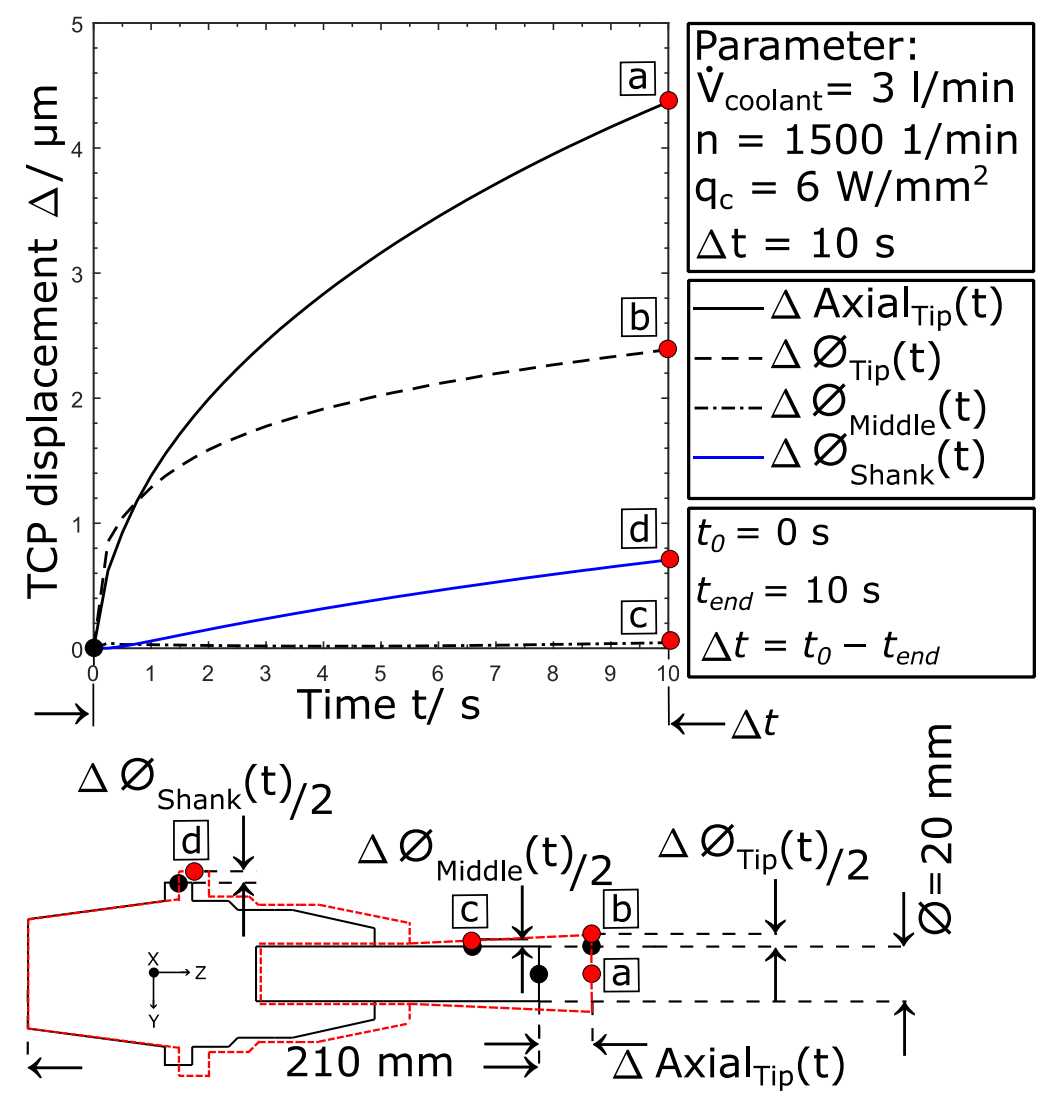

Fig. 5: Axial and radial TCP displacement 


\section{CONCLUSION AND OUTLOOK}

The paper shows a FEM formulation to simulate the TCP displacement by means of numerical simulation for a rotating end mill cutter under full-jet cooling. The developed unidirectional coupled approach is able to model the flow of the full jet cooling with its highly turbulent appearance. It calculates the transient temperature fields of the tool as well as the clamping device, which is resulting from the conjugate heat transfer. These body temperature fields can be used in subsequently coupled FE models to predict the thermally induced displacements. Thereby, the heat conduction due to transport processes of the internal energy is considered in the CFD model. Based on the calculated body temperature fields of the conjugate heat transport, the displacement of the TCP can be determined in the structural-mechanical part of the FSI.

In the further course of the investigations, the coupled model has to be verified in order to confirm the quality and suitability of the model approach. This is supposed to be achieved by the use of experimental data, gathered by an experimental rig (Fig. 6). For this, experiments will take place with rotating end mill cutter and jet cooling. The data is recorded until a steady state is reached with the used parameter set. Due to the time consuming character of the simulation the $\mathrm{FSI}$ results need to be extrapolated unti steady state is reached for comparison with the data gathered at the experimental rig. The experimental data and the FEM data will be compared to verify the quality of the used approach. Subsequent the FEM calculated displacements are going to be processed with the response surface regression. With this procedure, it is possible to state a mathematical model and link the varied parameter with the expected displacement in form of a characteristic diagram.

The experimental rig has the capacity to implement the heat of the cutting process by induction, under the conditions of dry machining as well as full jet cooling into the observed milling tool. Undoubtedly, the artificial production of the process heat due to milling operation and implementation into the end mill cutter is a weakness. Some aspects of the real cutting process are neglected like friction at the tool-chip interface. Major focus of the research is the thermal-elastic deformation of tool and clamping device, therefore, the chip formation is neglected and the real cutting process is simplified to a constant heat flow at the rake faces. Comparison of the calculated values with experimental one will revea the resemblance of the used approach. The displacement will be measured by the aid of a tactile eddy current sensor and the temperature of the tool at defined Locations will be detected with temperature sensors for verification and improvement of the developed FEM approach.

\section{ACKNOWLEDGMENTS}

The authors wish to thank the German Research Foundation (DFG) for funding the transregional Collaborative Research Center SFB/TR 96“Thermo-Energetische Gestaltung von Werkzeugmaschinen" (Aachen, Chemnitz, Dresden), Project number: 174223256, subproject A01 "Tool and clamping deformation".

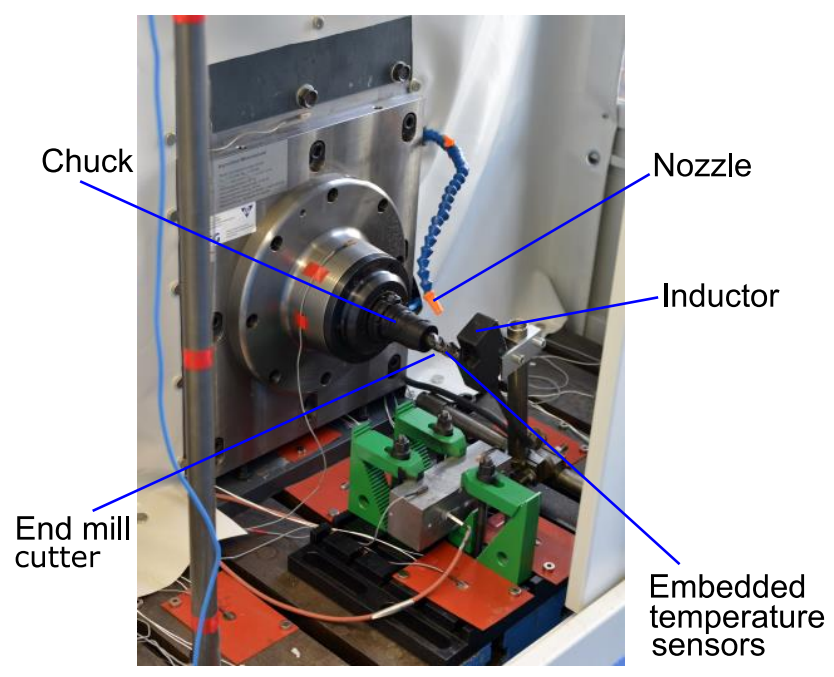

Fig. 6: Experimental rig for TCP displacement

\section{REFERENCES}

[Pabst 2008] Pabst, R., „Mathematische Modellierung der Wärmestromdichte zur Simulation des thermischen Bauteilverhaltens bei der Trockenbearbeitung“, Dissertation, Karsruhe: University Karlsruhe, Institut für Produktionstechnik, 2008

[Putz 2019] Putz, M., Glänzel, J., Regel, J., Bräunig, M., „Effects of cooling lubricant on the thermal regime in the working space of machine tools", Procedia Manufacturing, GCSM Lexington, Kentucky, USA, 2019, Volume 33, 2019, Pages 327-334

[Sauerzapf 2020] Sauerzapf, S., Vettermann, J., Naumann, A., Saak, J., Beitelschmidt, M., Benner, P., „Simulation of the thermal behavior of machine tools for efficient machine development and online correction of the Tool Center Point (TCP)-displacement", Special Interest Group Meeting on Thermal Issues Laboratory for Machine Tools and Production Engineering (WZL) of RWTH Aachen, Germany, February 2020

[Klocke 2017] Klocke, F., Döbbeler, B., Peng, B., Lakner, T., ,FE-simulation oft the cutting process under consideration of cutting fluid", Procedia CIRP, 16th CIRP Conference on Modelling of Machining Operations, Laboratory for Machine Tools and Production Engineering (WZL) of RWTH Aachen, Germany, 58 (2017) 341-346

[Oezkaya 2019] Oezkaya, E., lovkov, I., Biermann, D., „Fluid structure interaction (FSI) modelling of deep hole twist drilling with internal cutting fluid supply", CIRP Annals - Manufacturing Technology, 68 (2019) 81-84

[Semmler 2014] Semmler, U., Bräunig, M., Drossel, W., G., Schmidt, G., Wittstock, V., „Thermal deformations of cutting tools: measurement and numerical simulation", Prod. Eng. Res. Devel. (2014) 8:543-550

[Topinka 2020] Topinka, L., "Simulative und experimentelle Charakterisierung der Vollstrahlkühlung am spanenden Werkzeug", Master Thesis, Chemnitz: TU Chemnitz, Fakultät für Maschinenbau, 2020

[Menter 94] Menter, F. R., "Two-Equation Eddy-Viscosity Turbulence Models for Engineering Applications," AIAA Journal, Vol. 32, No. 8, August 1994, pp. 1598-1605.

[Perng 2011] Perng, YY., „Modeling Fluid Structure inteactions", Ansys Conference Houston 2011 